\title{
Concentration Dependence of the Sedimentation Coefficient of Flexible Macromolecules in Dilute Solution: Poly $(\alpha$-methylstyrene $)$ and Polystyrene ${ }^{*, * *}$
}

\author{
Akira Kotera, Takahide SaIto, ${ }^{* * *}$ and Takeshi HamadA ${ }^{* * *}$ \\ Department of Chemistry, Faculty of Science, Tokya Kyoiku \\ University, Otsuka, Bunkyo-ku, Tokyo, Japan.
}

(Received June 9, 1971)

\begin{abstract}
The coefficient $k_{\mathrm{s}}$ in the expression for the sedimentation coefficient, $1 / S=\left(1 / S_{0}\right)\left(1+k_{\mathrm{S}} c+\cdots\right)$, where $S$ and $S_{0}$ are the sedimentation coefficients at finite polymer concentration $c$ and at infinite dilution, respectively, was investigated experimentally for the systems of $\operatorname{poly}(\alpha$-methylstyrene $)$ and polystyrene in cyclohexane in the vicinity of the $\theta$-condition.

The $k_{\mathrm{s}}$-values at the $\theta$-condition were positive and were expressed by a linear function of the square root of molecular weight. The behavior of $k_{\mathrm{s}}$ in the region away from the $\theta$-condition could be satisfactorily described according to the theory of Pyun and Fixman when certain results obtained regarding the relationship between the segmentsegment interaction parameter and the expansion factor were used.

KEY WORDS Concentration Dependence / Dilute Solution / Expansion Factor / Frictional Properties / Poly $(\alpha$-methylstyrene) / Polystyrene / Sedimentation / $\theta$-Temperature /
\end{abstract}

The concentration dependence of the sedimentation coefficient is expressed by the following form

$$
1 / S^{0}=\left(1 / S_{0}{ }^{0}\right)\left(1+k_{\mathrm{s}} c+\cdots\right)
$$

where $S^{0}$ and $S_{0}{ }^{0}$ are the sedimentation coefficient at a finite polymer concentration $c$, and at infinite dilution, respectively; $k_{\mathrm{s}}$ may be considered to be a parameter of the hydrodynamic interaction between sedimenting polymer molecules.

Some theoretical treatments, each employing a different model, have been reported for $k_{\mathrm{s}}{ }^{1,2}$ These theories, however, did not coincide well with experimental results, which indicated that

* This paper has been taken partly from a doctoral dissertation submitted by Takeshi Hamada to Tokyo Kyoiku University, 1969.

** This study was supported by both the Ministry of Education (JAPAN) and the Matsunaga Science Foundation.

*** Present address: Department of Food Science and Technology, Tokyo University of Fisheries, Konancho, Minato-ku, Tokyo, Japan.

**** Present address: Department of Chemistry, School of Medicine, Kyorin University, Miyashita-cho, Hachioji, Tokyo, Japan. $k_{\mathrm{s}}$ in a poor or $\theta$-solvent was smaller than that in a good solvent and that $k_{\mathrm{s}}$ decreased with decreasing temperature.

In 1962, Yamakawa proposed a theory ${ }^{3}$ concerning $k_{\mathrm{s}}$ on the basis of the KirkwoodRiseman approach and stated that $k_{\mathrm{s}}$ vanished at the $\theta$-condition and increased with increasing temperature. On the other hand, Pyun and Fixman ${ }^{4}$ treated the macromolecular solutes as suspended spheres, taking account of the longranged hydrodynamic interaction, and stated that $k_{\mathrm{s}}$ increased with increasing temperature, having a positive value at the $\theta$-condition.

There has been a limited amount of experimental data which permitted the determination of the temperature dependence of $k_{\mathrm{s}}{ }^{5}$ The authors therefore investigated the temperature dependence of $k_{\mathrm{s}}$ in the vicinity of $\theta$-condition, and attempted to describe the data as a function of the expansion factor. A detailed comparison of the experimental results with the theory of Pyun and Fixman was also made. For this purpose, sedimentation and viscosity of poly $(\alpha-$ methylstyrene) and polystyrene in cyclohexane were measured at several temperatures above and 
below the $\theta$-point.

\section{EXPERIMENTAL}

\section{Samples}

The four $\operatorname{poly}(\alpha$-methylstyrene) samples used were anionically polymerized at Nagoya University and were kindly supplied by Prof. M. Nagasawa. The polystyrene samples used, which, as shown below, had very narrow molecular weight distributions, were commercially distributed by Pressure Chemicals as the standard samples for gel-permeation chromatography.

\section{Solvents}

Cyclohexane was purified by the usual method and fractionally distilled over sodium. The fraction obtained in the range of bp from 80.7 to $80.8^{\circ} \mathrm{C}$ was used $\left[n_{\mathrm{D}}^{25} 1.4233, d^{25} 0.7743(\mathrm{~g} / \mathrm{ml})\right]$.

Purified toluene was obtained by the usual method [bp $110.5-110.6^{\circ} \mathrm{C}, n_{\mathrm{D}}^{25} 1.4942, d^{25} 0.8629$ $(\mathrm{g} / \mathrm{m} l)] . \quad \theta$-Temperature: Determination of the $\theta$-temperature for the poly $(\alpha$-methylstyrene $)-$ cyclohexane system was carried out by using a Shimadzu Light-Scattering Photometer with a poly $(\alpha$-methylstyrene) sample. This sample was prepared with $\mathrm{BF}_{3}$ catalyst at Kyoto University and kindly supplied by Prof. S. Okamura. A value of $38.2 \pm 0.6^{\circ} \mathrm{C}$ was obtained for the $\theta$ temperature of poly $(\alpha$-methylstyrene $)$ in cyclohexane from measurements at temperatures within the range 34 to $45^{\circ} \mathrm{C}$. This value is very close to the $38.0^{\circ} \mathrm{C}$ reported previously from this laboratory ${ }^{6}$ and falls within the ranges reported by several other investigators. ${ }^{7-9}$

The $\theta$-temperature for the polystyrene-cyclohexane system was assumed to be $35.0^{\circ} \mathrm{C}$, as determined from the light-scattering measurement. ${ }^{6}$

\section{Molecular-Weight Determination}

Number-Average Molecular-Weight. Numberaverage molecular weights were determined in toluene by using two kinds of apparatus. One was a Mechrolab High Speed Membrane Osmometer, model 502, which was used for $\operatorname{poly}(\alpha-$ methylstyrene) samples at $37.0 \pm 0.2^{\circ} \mathrm{C}$, and the other a Hallikainen Automatic Osmometer, model $1361 \mathrm{BS} 1$, for polystyrene samples at $35.0 \pm 0.2^{\circ} \mathrm{C}$.

Weight-Average Molecular Weight. Weightaverage molecular weights were determined by using an Aminco Light-Scattering Photometer, at $38.0 \pm 0.2^{\circ} \mathrm{C}$ for $\operatorname{poly}(\alpha$-methylstyrene $)$-cyclohexane and at $35.0 \pm 0.2^{\circ} \mathrm{C}$ for polystyrenecyclohexane. The refractive index increment, $\mathrm{d} n / \mathrm{d} c$, for $436 \mathrm{~m} \mu$ unpolarized light was 0.204 $\mathrm{ml} / \mathrm{g}$ for $\operatorname{poly}(\alpha$-methylstyrene $)$ in cyclohexane at $38.0^{\circ} \mathrm{C}$ and $0.181 \mathrm{ml} / \mathrm{g}$ for polystyrene in cyclohexane at $35.0^{\circ} \mathrm{C}{ }^{10}$

Partial Specific Volume. The partial specific volume of poly $(\alpha$-methylstyrene) in cyclohexane at $38.0^{\circ} \mathrm{C}$ was found to be $0.889 \mathrm{ml} / \mathrm{g}$ with a pycnometer having a volume of $c a .12 \mathrm{ml}$, which is very close to a reported value of $0.886 \mathrm{~m} l / \mathrm{g}$ at $39.0^{\circ} \mathrm{C} .^{7}$

A value of $0.928 \mathrm{ml} / \mathrm{g}$ was used for polystyrene in cyclohexane at $35.0^{\circ} \mathrm{C}$ which had been reported by Mandelkern, et al. ${ }^{10}$

Sedimentation Measurement. Sedimentation velocity experiments were carried out in cyclohexane at five temperatures above and below the $\theta$-point, using a Hitachi Model UCA-1 ultracentrifuge equipped with a schlieren optical system. Temperatures were controlled within $\pm 0.2^{\circ} \mathrm{C}$ and a $12 \mathrm{~mm}$-centerpiece used. In all runs, the distance traversed by a schlieren peak was kept shorter than $3 \mathrm{~mm}$ to reduce the corrections for the pressure and radial dilution effects.

For organic solvents the pressure effect upon sedimentation rate is generally appreciable due to their large compressibilities. It is usually corrected by using the following (Fujita's) equation: ${ }^{11}$

$$
S^{\mathrm{app}}=S^{0}\left\{1-G\left[\left(r_{\mathrm{p}} / r_{\mathrm{m}}\right)^{2}-1\right]\right\}
$$

where

$$
S^{\mathrm{app}}=\ln \left(r_{\mathrm{p}} / r_{\mathrm{m}}\right) /\left\{\omega^{2}\left(t-t_{0}\right)\right\}
$$

Here $S^{\mathrm{app}}$ is the sedimentation coefficient at a time $t, S^{0}$ the sedimentation coefficient for the initial concentration at $1 \mathrm{~atm} ., r_{\mathrm{p}}$ the position of the maximum refractive index gradient, $r_{\mathrm{m}}$ the position of the meniscus, $\omega$ the angular velocity, $t_{0}$ the initial time correction, and $G$ the parameter which includes the pressure and radial dilution effects.

If $S^{\mathrm{app}}$ is plotted against $\left(r_{\mathrm{p}} / r_{\mathrm{m}}\right)^{2}-1$ according to eq 2 , the corrected sedimentation coefficient $S^{0}$ can be determined from the intercept. However, since the initial time correction $t_{0}$ is not known in advance, it is quite difficult to determine $S^{0}$ without ambiguity. In this work, $t_{0}$ 
was determined by extrapolating the position of the maximum index gradient to that of the meniscus, since a linear relationship was found experimentally to exist between $\ln \left(r_{\mathrm{p}} / r_{\mathrm{m}}\right)$ and time $t$ as long as the sedimentation distance remained small.

A new method, called the "best fit" method, was proposed recently to determine a reasonable value of $S^{0}{ }^{7,12}$ In this method, $S^{\text {app }}$ is assumed to be a function of $t_{0}$ as shown in eq 3 , since quantities such as $r_{\mathrm{p}}, r_{\mathrm{m}}, \omega$, and $t$ are directly obtained. Then, both $S^{0}$ and $t_{0}$ which give best fit to eq 2 are determined from the plots of $S^{a p p}$ vs. $\left(r_{\mathrm{p}} / r_{\mathrm{m}}\right)^{2}-1$ so that the standard deviation of the difference between the left-hand term and right-hand term of eq 2 becomes a minimum.

For comparison of the empirical method used with the best fit method, ${ }^{7,12}$ the authors applied the latter method to the data obtained at 44100 $\mathrm{rpm}$ and at $37600 \mathrm{rpm}$ for $\operatorname{poly}(\alpha$-methylstyrene $)$ sample of PMS-227 in cyclohexane $\left(38.2^{\circ} \mathrm{C}, c_{0}=\right.$ $0.304 \mathrm{~g} / \mathrm{d} l$ ). The relative differences in the values of $S^{0}$ from the two methods were less than $3 \%$ at $44100 \mathrm{rpm}$ and $2 \%$ at $37600 \mathrm{rpm}$. It therefore appeared that the data obtained by the present method were reasonable.

When ultracentrifugations are carried out at different speeds, it is necessary to know how much the $S^{0}$-value is affected by rotor speed.

Figure 1 shows the results for poly $(\alpha-$-methylstyrene) sample PMS-227 in cyclohexane $\left(38.2^{\circ} \mathrm{C}\right.$, $\left.c_{0}=0.304 \mathrm{~g} / \mathrm{d} l\right)$ at different velocities. It is found from Figure 1 that the intercepts of the straight lines for different velocities do not agree perfectly with each other, but the relative differences in $S^{0}$-values are less than $3 \%$. Therefore, it seems that the sedimentation coefficient at initial con-

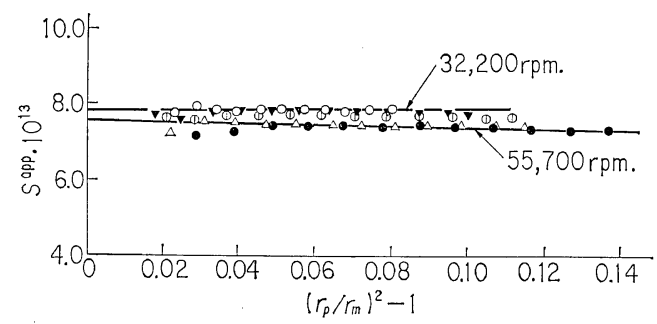

Figure 1. Plots of $S^{\mathrm{app}} v s .\left(r_{\mathrm{p}} / r_{\mathrm{m}}\right)^{2}-1$ for PMS-227 in cyclohexane $\left(38.0^{\circ} \mathrm{C}, c_{0}=0.304 \mathrm{~g} / \mathrm{d} l\right)$ at different speeds: $\bigcirc, 32200 \mathrm{rpm} ; \boldsymbol{\nabla}, 37600 \mathrm{rpm}$; (1) 44100 rpm; $\triangle, 51900 \mathrm{rpm} ; \bullet, 55600 \mathrm{rpm}$.
Table I. Experimental conditions in sedimentation measurements

\begin{tabular}{|c|c|c|}
\hline Sample & $\begin{array}{l}\text { Rotor speed, } \\
\text { rpm }\end{array}$ & Temp, ${ }^{\circ} \mathrm{C}$ \\
\hline \multicolumn{3}{|c|}{$\operatorname{Poly}(\alpha$-methylstyrene) } \\
\hline PMS-6 & about 55430 & $\begin{array}{l}34.0,38.2,42.0 \\
46.0,50.0\end{array}$ \\
\hline PMS-03 & about 47300 & " \\
\hline PMS-227 & about 43700 & $" \prime$ \\
\hline PMS-10 & about 37290 & " \\
\hline \multicolumn{3}{|l|}{ Polystyrene } \\
\hline PS-9 & about 51200 & $\begin{array}{ll}30.0, & 35.0, \\
45.0, & 50.0\end{array}$ \\
\hline PS-16 & about 43700 & " \\
\hline PS-41 & about 37290 & $\begin{array}{l}33.0,35.0,40.0 \text {, } \\
45.0,50.0\end{array}$ \\
\hline
\end{tabular}

centration is not greatly affected by the velocity employed. In this study, the authors selected the optimum velocities by taking into account the molecular weight as shown in Table I.

The sedimentation coefficient at infinite dilution, $S_{0}{ }^{0}$, and the concentration dependence coefficient, $k_{\mathrm{s}}$, were determined by using corrected values of $S^{0}$ obtained at several concentrations through extrapolation to infinite dilution according to eq 1 .

Viscosity Measurement. Measurements of intrinsic viscosity were carried out at the same temperatures as in the sedimentation measurements by using an Ubbelohde dilution type viscometer. The intrinsic viscosity, $[\eta]$, and Huggins' constant, $k^{\prime}$, were determined by use of the Huggins' equation.

\section{RESULTS}

Molecular-Weight Heterogeneity. The values of number-average molecular weight $\left(\bar{M}_{n}\right)$ and weight-average molecular weight $\left(\bar{M}_{w}\right)$ for each sample are summarized in Table II together with the second virial coefficient $B_{2}$ from osmotic pressure and $A_{2}$ from light scattering. The $\bar{M}_{w} / \bar{M}_{n}$-values given in the last column of Table II are very close to unity. It is therefore assumed that all samples used in this work were sufficiently homogeneous with respect to molecular weight.

Sedimentation Coefficient. The results summarized in Tables III and IV show that the $S_{0}{ }^{0}$ values for these samples increase with increasing temperature. This tendency is reasonable because 
Table II. Characterization of samples

\begin{tabular}{ccccc}
\hline \multirow{2}{*}{ Sample } & \multicolumn{2}{c}{$\begin{array}{c}\text { Osmotic-pressure } \\
\text { measurement }\end{array}$} & \multicolumn{2}{c}{$\begin{array}{c}\text { Light-scattering } \\
\text { measurement }^{\mathrm{b}}\end{array}$} \\
\cline { 2 - 5 } & $\begin{array}{c}\bar{M}_{n} \\
\times 10^{-4}\end{array}$ & $\begin{array}{c}B_{2} \\
\times 10^{4}\end{array}$ & $\begin{array}{c}\bar{M}_{w} \\
\times 10^{-4}\end{array}$ & $\begin{array}{c}A_{2} \\
\times 10^{4}\end{array}$ \\
\hline
\end{tabular}

\begin{tabular}{|c|c|c|c|c|c|}
\hline \multicolumn{6}{|c|}{$\operatorname{Poly}(\alpha$-methylstyrene $)$} \\
\hline PMS-6 & - & - & 4.9 & -0.5 & - \\
\hline PMS-03 & 11.9 & 4.0 & $12.1^{\mathrm{c}}$ & $0.0^{\mathrm{c}}$ & $1.0_{3}$ \\
\hline PMS-227 & - & - & $18.3^{\mathrm{c}}$ & $0.0^{\mathrm{c}}$ & - \\
\hline PMS-10 & 25.9 & 3.5 & $26.8^{c}$ & $0.0^{\mathrm{c}}$ & $1.0_{3}$ \\
\hline \multicolumn{6}{|c|}{ Polystyrene } \\
\hline PS-9 & 10.6 & 6.9 & 10.9 & 0.0 & $1.0_{3}$ \\
\hline PS-16 & 15.9 & 4.3 & 17.0 & 0.0 & $1.0_{6}$ \\
\hline PS-41 & 37.6 & 4.3 & 42.2 & 0.0 & $1.1_{2}$ \\
\hline
\end{tabular}

a In toluene at $37.0^{\circ} \mathrm{C}$ for poly $(\alpha$-methylstyrene $)$ and at $35.0^{\circ} \mathrm{C}$ for polystyrene.

b In cyclohexane at $38.0^{\circ} \mathrm{C}$ for $\operatorname{poly}(\alpha$-methylstyrene) and at $35.0^{\circ} \mathrm{C}$ for polystyrene.

c Determined in cyclohexane at $38.0^{\circ} \mathrm{C}$ by A. Wada in this laboratory.

the sedimentation coefficient should increase with increasing temperature owing to the reduction in solvent viscosity as well as in density.

(1) In Figure 2, the values of $\log S_{0 \theta}^{0}$ for $\operatorname{poly}\left(\alpha\right.$-methylstyrene) are plotted against $\log \bar{M}_{w}$, together with the values obtained by Nagasawa, et al., ${ }^{7}$ and by Kurata, et al. ${ }^{8}$ Although the values by these two groups were obtained in cyclohexane at $39.0^{\circ} \mathrm{C}$, it is fair to say that the present data agree reasonably well with them.

The relationship between $S_{0 \theta}^{0}$ and $\bar{M}_{w}$ was approximated by the following form*

$$
S_{0 \theta}^{0}=1.93 \times 10^{-15} \bar{M}_{w}^{\frac{1}{2}}
$$

(2) The results of $S_{0 \theta}^{0}$ for the polystyrenecyclohexane system at $35.0^{\circ} \mathrm{C}$ are plotted against $\bar{M}_{w}$ in Figure 3, wherein the reported data ${ }^{5,10,13-15}$ for more heterogeneous samples are also included for comparison.

It is found from Figure 3 that the present data are in close agreement with those of other studies. The authors determined the following relationship between $S_{0 \theta}^{0}$ and $\bar{M}_{w}$ by fitting a straight line to these and previous data

* The relationships for poly ( $\alpha$-methylstyrene) in cyclohexane at $39^{\circ} \mathrm{C}$ were reported to be $S_{0}{ }^{0}=2.04 \times$ $10^{-15} \bar{M}^{\frac{1}{2}}$ by Nagasawa, et al., ${ }^{7}$ and $S_{0} 0=2.00 \times$ $10^{-15} \bar{M}^{\frac{1}{2}}$ by Kurata, et al., ${ }^{8}$ respectively.
Table III. Results of sedimentation and viscosity measurements for $\operatorname{Poly}(\alpha$-methylstyrene) in cyclohexane near the $\theta$-temperature

\begin{tabular}{llcccc}
\hline Sample & $T,{ }^{\circ} \mathrm{C}$ & $S_{0}{ }^{\circ}$ (sved) & $k_{\mathrm{s}}, \mathrm{d} l / \mathrm{g}$ & {$[\eta], \mathrm{d} l / \mathrm{g}$} & $k^{\prime}$ \\
\hline PMS-6 & 34.0 & $3.9_{0}$ & $0.1_{4}$ & $0.16_{1}$ & 1.0 \\
& $38.2(\theta)^{\mathrm{c}}$ & $4.2_{3}$ & $0.1_{7}$ & $0.16_{6}$ & $0.8_{6}$ \\
& 42.0 & $4.5_{0}$ & $0.2_{0}$ & $\left(0.17_{0}\right)^{\mathrm{a}}$ & - \\
& 46.0 & $4.8_{2}$ & $0.2_{0}$ & $0.17_{3}$ & $0.7_{1}$ \\
& 50.0 & $5.0_{9}$ & $0.2_{1}$ & $0.17_{7}$ & $0.6_{0}$ \\
PMS-03 & 34.0 & $6.0_{9}$ & $0.2_{3}$ & $\left(0.24_{4}\right)^{\mathrm{b}}$ & - \\
& $38.2(\theta)^{\mathrm{c}}$ & $6.5_{6}$ & $0.2_{7}$ & $0.25_{3}$ & $0.7_{4}$ \\
& 42.0 & $6.9_{9}$ & $0.3_{4}$ & $0.26_{0}$ & $0.7_{9}$ \\
& 46.0 & $7.4_{7}$ & $0.3_{8}$ & $0.26_{8}$ & $0.6_{8}$ \\
& 50.0 & $8.0_{3}$ & $0.4_{1}$ & $0.28_{0}$ & $0.5_{6}$ \\
PMS-227 & 34.0 & $7.8_{8}$ & $0.2_{4}$ & $0.31_{6}$ & $0.9_{2}$ \\
& $38.2(\theta)^{\mathrm{c}}$ & $8.4_{7}$ & $0.3_{3}$ & $0.33_{0}$ & $0.7_{7}$ \\
& 42.0 & $9.0_{1}$ & $0.3_{7}$ & $0.34_{3}$ & $0.7_{7}$ \\
& 46.0 & $9.6_{3}$ & $0.4_{2}$ & $0.35_{6}$ & $0.7_{1}$ \\
& 50.0 & 10.0 & $0.4_{4}$ & $0.37_{6}$ & $0.6_{1}$ \\
PMS-10 & 34.0 & $9.2_{9}$ & $0.3_{2}$ & $0.36_{1}$ & $0.9_{1}$ \\
& $38.2(\theta)^{\mathrm{c}}$ & 10.1 & $0.4_{6}$ & $0.38_{2}$ & $0.8_{1}$ \\
& 42.0 & 10.8 & $0.5_{3}$ & $0.39_{4}$ & $0.7_{9}$ \\
& 46.0 & 11.3 & $0.5_{6}$ & $0.41_{4}$ & $0.6_{8}$ \\
& 50.0 & 12.0 & $0.5_{7}$ & $0.43_{0}$ & $0.7_{0}$ \\
\hline
\end{tabular}

a Interpolated value.

b Extrapolated value.

c $(\theta), \theta$-temperature.

Table IV. Results of sedimentation and viscosity measurements for polystyrene in cyclohexane near the $\theta$-temperature

\begin{tabular}{llcccc}
\hline Sample & $T,{ }^{\circ} \mathrm{C}$ & $S_{0}{ }^{0}$ (sved) & $k_{\mathrm{s}}, \mathrm{d} l / \mathrm{g}$ & {$[\eta], \mathrm{d} l / \mathrm{g}$} & $k^{\prime}$ \\
\hline PS-9 & 30.0 & $4.5_{0}$ & $0.1_{9}$ & $0.24_{4}$ & $0.6_{7}$ \\
& $35.0(\theta)$ & $4.8_{8}$ & $0.2_{6}$ & $0.25_{4}$ & $0.6_{8}$ \\
& 40.0 & $5.4_{4}$ & $0.3_{6}$ & $0.26_{4}$ & $0.7_{3}$ \\
& 45.0 & $5.8_{9}$ & $0.4_{1}$ & $0.27_{3}$ & $0.7_{0}$ \\
& 50.0 & $6.2_{8}$ & $0.4_{4}$ & $0.28_{6}$ & $0.5_{9}$ \\
PS-16 & 30.0 & $5.9_{7}$ & $0.2_{1}$ & $0.30_{8}$ & $0.5_{8}$ \\
& $35.0(\theta)$ & $6.4_{8}$ & $0.3_{3}$ & $0.33_{8}$ & $0.5_{0}$ \\
& 40.0 & $6.9_{2}$ & $0.3_{6}$ & $\left(0.35_{5}\right)^{\mathrm{a}}$ & - \\
& 45.0 & $7.5_{8}$ & $0.4_{6}$ & $\left(0.37_{0}\right)^{\mathrm{a}}$ & - \\
& 50.0 & $8.2_{4}$ & $0.5_{5}$ & $0.38_{0}$ & $0.4_{6}$ \\
& 33.0 & 10.0 & $0.4_{4}$ & $\left(0.49_{6}\right)^{\mathrm{b}}$ & - \\
& $35.0(\theta)$ & $9.9_{1}$ & $0.3_{7}$ & $0.51_{3}$ & $0.7_{1}$ \\
& 40.0 & 10.9 & $0.6_{4}$ & $0.56_{4}$ & $0.6_{1}$ \\
& 45.0 & 11.9 & $0.8_{3}$ & $0.59_{5}$ & $0.5_{8}$ \\
& 50.0 & 12.7 & $0.9_{3}$ & $0.63_{0}$ & $0.6_{6}$ \\
\hline
\end{tabular}

a Interpolated value.

b Extrapolated value.

c $(\theta), \theta$-temperature. 


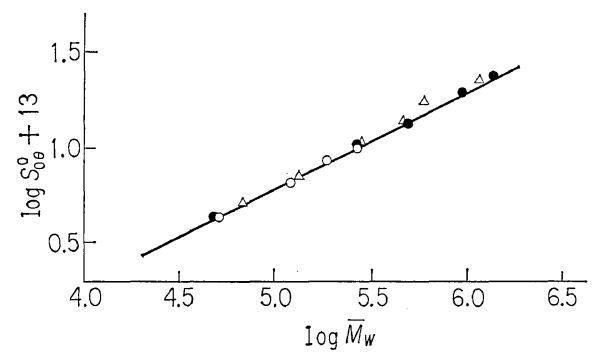

Figure 2. Double logarithmic plots of $S_{0 \theta}^{0} v s . \bar{M}_{w}$ for $\operatorname{poly}(\alpha$-methylstyrene) in cyclohexane at the $\theta$-condition: $\bigcirc$, this work $\left(38.2^{\circ} \mathrm{C}\right) ; \triangle$, Nagasawa, et al. ${ }^{7} ; \bigcirc$, Kurata, et al. ${ }^{8}$; solid line, obtained from the data in this work.

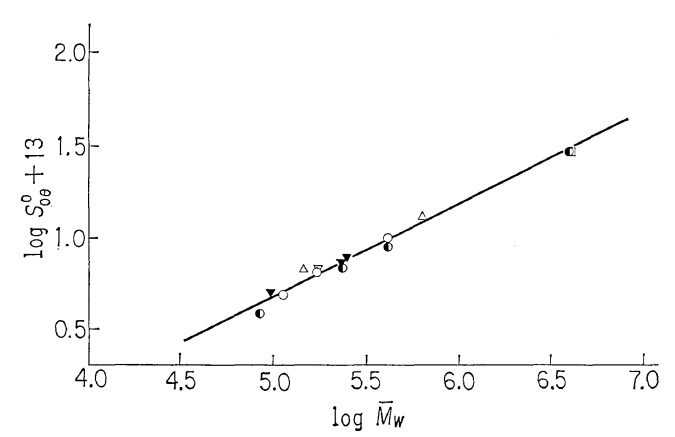

Figure 3. Double logarithmic plots of $S_{0 \theta}^{0} v s . \bar{M}_{w}$ for polystyrene in cyclohexane at the $\theta$-temperature $\left(35.0^{\circ} \mathrm{C}\right): \bigcirc$, this work; $\triangle$, Wales, et al. ${ }^{14} ; \square$, McIntyre, et al. ${ }^{10} ; \nabla$, Billick $^{15} ; \boldsymbol{D}$, Homma, et al. ${ }^{13}$; $\nabla$, Billick ${ }^{5}$; solid line, obtained from the data both in this work and in earlier reports.

$$
S_{0 \theta}^{0}=1.52 \times 10^{-15} \bar{M}_{w}^{\frac{1}{2}}
$$

Intrinsic Viscosity. The results from the viscosity measurements are listed in Tables III and IV for $\operatorname{poly}(\alpha$-methylstyrene) and polystyrene, respectively.

(1) The $[\eta]_{\theta}$-values for poly $(\alpha$-methylstyrene $)$ obtained in this work are plotted against $\bar{M}_{w}$ in Figure 4 which also includes the data obtained at $39^{\circ} \mathrm{C}$ by Nagasawa, et al.,$^{7}$ and at $37.0^{\circ} \mathrm{C}$ by Cowie, et al. ${ }^{9}$ Figure 4 shows that all the plotted data agree with each other in spite of the temperature difference.

(2) In Figure 5, the values of $[\eta]_{\theta}$ for polystyrene are plotted against $\bar{M}_{w}$ plus those obtained by other investigators ${ }^{10,13}$ in cyclohexane at $35.0^{\circ} \mathrm{C}$. It can be seen that the data from this work agree with those of earlier authors.

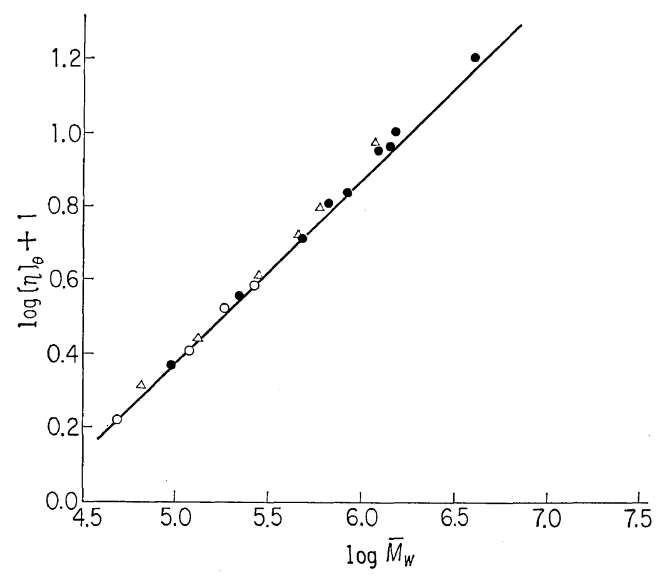

Figure 4. Double logarithmic plots of $[\eta]_{\theta} v s . \bar{M}_{w}$ for poly $(\alpha$-methylstyrene $)$ in cyclohexane at the $\theta$ condition: $\bigcirc$, this work $\left(38.2^{\circ} \mathrm{C}\right) ; \triangle$, Nagasawa, et al. ${ }^{7}\left(39.0^{\circ} \mathrm{C}\right)$; O Cowie, et al. $9^{9}\left(37.2^{\circ} \mathrm{C}\right)$; solid line, obtained from the data in this work.

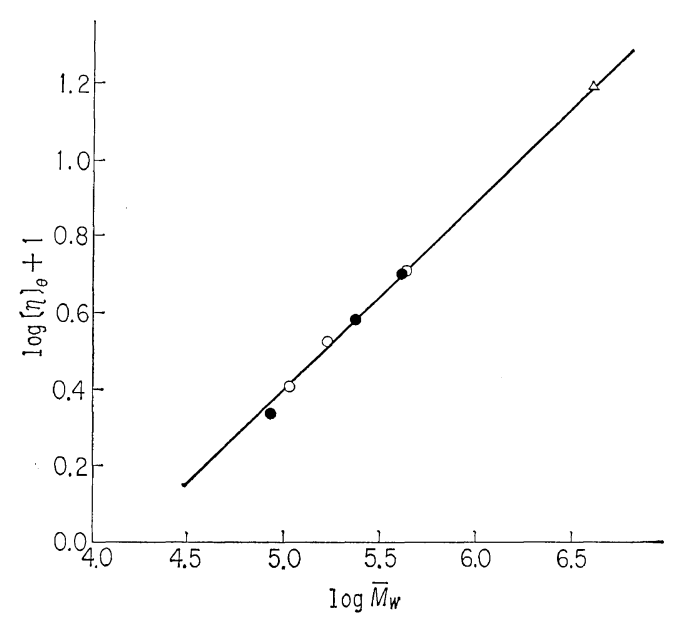

Figure 5. Double logarithmic plots of $[\eta]_{\theta} v s . \bar{M}_{w}$ for polystyrene in cyclohexane at the $\theta$-temperature $\left(35.0^{\circ} \mathrm{C}\right): \bigcirc$, this work; $\triangle$, McIntyre, et al. ${ }^{10}$; $\bigcirc$, Homma, et al. ${ }^{13}$; solid line, obtained from the data in this work.

Variation of $k_{\mathrm{s}}$-Value with Temperature. The results listed in Tables III and IV show that $k_{\mathrm{s}}$ for each sample is apparrently positive at the $\theta$ point and tends to increase with increasing temperature.

\section{DISCUSSION}

In the introductory section, it was pointed out 
that two different theories were recently proposed for the description of $k_{\mathrm{s}}$-behavior in dilute polymer solution, one by Yamakawa ${ }^{3}$ and the other by Pyun and Fixman. ${ }^{4}$

According to Yamakawa, ${ }^{3} k_{\mathrm{s}}$ is given by

$$
k_{\mathrm{s}}=1.65[\eta] \lambda\left(x_{1}\right) \log \left(1+5.73 x_{1}\right)
$$

where

$$
x_{1}=z / \alpha_{\eta}{ }^{3} .
$$

Here $\lambda\left(x_{1}\right)$ is a function of $x_{1}, z$ is the parameter of volume exclusion, and $\alpha_{\eta}$ is the viscosity expansion factor. This equation shows that $k_{\mathrm{s}}$ vanishes at the $\theta$-condition $\left(x_{1}=0\right)$, and that it increases with increasing temperature, because $\lambda\left(x_{1}\right)$ is nearly constant for $x_{1}$ near the $\theta$-condition.

According to Pyun and Fixman, ${ }^{4} k_{\mathrm{s}}$ in the vicinity of $\theta$-condition can be simply expressed by the following form, if higher terms in the series expansion of their original equation are neglected

$$
k_{\mathrm{s}}=C_{1}\left(a^{3} / M\right)\left(K_{0}+K_{1} x_{2}\right)
$$

where

$$
x_{2}=C_{2}(1-\theta / T) a^{-3} .
$$

Here $C_{1}, C_{2}, K_{0}$, and $K_{1}$ are positive constants, and $a$ is the radius of a polymer chain. According to this theory, $k_{\mathrm{s}}$ increases with increasing temperature and has a positive finite value at the $\theta$-condition.

Therefore, we find that the essential difference between the above-mentioned two theories is in the description of the $k_{\mathrm{s}}$-behavior at the $\theta$-condition. From the present experimental results in the vicinity of $\theta$-conditions for both $\operatorname{poly}(\alpha-$ methylstyrene) and polystyrene, it is found that the $k_{\mathrm{s}}$-values at the $\theta$-condition are positive (see Tables III and IV). This result as well as those recently obtained by the other investigators ${ }^{5,7,8,12}$ supports the theory of Pyun and Fixman rather than the Yamakawa theory.

Treatment by the Pyun and Fixman Theory

According to Pyun and Fixman, ${ }^{4}$ the detailed expression for $k_{\mathrm{s}}$ reads

$k_{\mathrm{s}}=(4 / 300)(M / N \pi)^{2}\left[\left(1-\bar{v} \rho_{0}\right) /\left(6 \eta_{0} S_{0}{ }^{0}\right)\right]^{3}[7.16-\kappa(A)]$

where $M$ is the polymer molecular weight, $N$ the
Avogadro number, $\bar{v}$ the partial specific volume of polymer, $\rho_{0}$ and $\eta_{0}$ the density and the viscosity of solvent, respectively, and $S_{0}{ }^{0}$ the sedimentation coefficient for infinite dilution at $1 \mathrm{~atm}$. Furthermore, $\kappa(\boldsymbol{A})$ is a function dependent upon a model chosen to describe the hydrodynamic interaction between the sedimenting molecules, and it monotonically decreases with increasing $A$. Here $A$ is a thermodynamic interaction parameter defined by

$$
A=\left(3 n^{2} X\right) /\left(8 \pi a^{3}\right)
$$

where $n$ is the number of segments per molecule, $X$ the second virial coefficient for segmentsegment interaction and, $a$ the radius of the sphere.

According to the Stokes formula and the wellknown Svedberg equation, ${ }^{16}$ the frictional expansion factor, $\alpha_{\mathrm{f}}$, is represented by

$$
\begin{aligned}
\alpha_{\mathrm{f}} & =a / a_{\theta}=\left(\eta_{0 \theta} / \eta_{0}\right)\left(f / f_{\theta}\right) \\
& =\left\{\left(1-\bar{v} \rho_{0}\right) /\left(1-\bar{v}_{\theta} \rho_{0 \theta}\right)\right\}\left\{\left(S_{0 \theta}^{0} \eta_{0 \theta}\right) /\left(S_{0}^{0} \eta_{0}\right)\right\}
\end{aligned}
$$

where $f$ is the frictional coefficient and the subscript $\theta$ denotes the $\theta$-temperature.

Using eq 10 , eq 8 may be rewritten

$$
\begin{aligned}
k_{\mathrm{s}}= & (4 / 300)(1 / N \pi)^{2}\left[\left(1-\bar{v}_{\theta} \rho_{0 \theta}\right) /\left(6 \eta_{0 \theta} K_{\mathrm{s} \theta}\right)\right]^{3} \\
& \times[7.16-\kappa(A)] M^{\frac{1}{2}} \alpha_{\mathrm{f}}{ }^{3}
\end{aligned}
$$

where $K_{\mathrm{s} \theta}$ is a constant in the empirical relation between $S_{0 \theta}^{0}$ and $M^{\frac{1}{2}}$, i.e., $S_{0 \theta}^{0}=K_{\mathrm{s} \theta} M^{\frac{1}{2}}$.

According to eq $11, k_{\mathrm{s}}$ is considered to be a function of both the segment-segment interaction parameter, $A$, defined in eq 9 , and the frictional expansion factor, $\alpha_{\mathrm{f}}$. Since the segment-segment interaction can be related to the volume expansion by the two-parameter theory of dilute polymer solution, the authors attempt to represent $k_{\mathrm{s}}$ as a function of the expansion factor in the following discussion.

If the sedimenting particle is approximated by a soft sphere of uniform segment density, the radius of the sphere, $a$, may be taken to be equal to the root-mean-square radius of gyration $\left\langle s^{2}\right\rangle^{\frac{1}{2}}$. Then $A$ in eq 9 may be rewritten

$$
A=\left(3 n^{2} X\right) /\left(8 \pi\left\langle s^{2}\right\rangle_{0}{ }^{3 / 2} \alpha^{3}\right)
$$

where $\alpha=\left(\left\langle s^{2}\right\rangle \mid\left\langle s^{2}\right\rangle_{0}\right)^{\frac{1}{2}}$.

Here $\alpha$ is the expansion factor, and $\left\langle s^{2}\right\rangle_{0}$ is the value of $\left\langle s^{2}\right\rangle$ at the unperturbed state. 
The term $n^{2} X /\left\langle s^{2}\right\rangle_{0}^{3 / 2}$ in eq 12 is proportional to the parameter of the volume exclusion, $z$. Consequently, one can rewrite eq 12 as follows

$$
A=3 \pi^{\frac{1}{2}}\left(z / \alpha^{3}\right)
$$

where $z=\left(n^{2} X\right)\left(4 \pi\left\langle s^{2}\right\rangle_{0}\right)^{-3 / 2}$.

Various relations between $z$ and $\alpha$ have been derived theoretically by several researchers. In this case, the following type of relationship may be employed. ${ }^{*, 17}$

$$
\alpha^{3}=1+2 z
$$

Then, eq 13 becomes

$$
A=1.5 \pi^{\frac{1}{2}}\left(1-\alpha^{-3}\right)
$$

Although any general relationship between the expansion factors has not been proposed, it seems reasonable to assume that $\alpha=\alpha_{\mathrm{f}}=\alpha_{\eta}$ in the vicinity of $\theta$-condition. In the following discussion, the authors employ $\alpha_{\eta}$ for the expansion factor mentioned above, because it is more accurately obtainable experimentally than the others. Further, the weight-average molecular weight is used for $M$ in eq 11 , because the molecular weight distribution of samples used was very narrow and the experimental accuracy in the measurement of $\bar{M}_{w}$ is higher than that of $\bar{M}_{n}$.

\section{Comparison with Experiment}

When the $S_{0 \theta}^{0}-\bar{M}_{w}^{\frac{1}{2}}$ relations in the preceding section i.e., eq 4 and 5 , and the values for $\bar{v}_{\theta}$, $\rho_{0 \theta}$, and $\eta_{0 \theta}$ listed in Table $\mathrm{V}$ are used for the calculation of the bracketed term in eq 11, the following equation is derived for each polymersolvent system

$$
k_{\mathrm{s}} / \bar{M}_{w}{ }^{\frac{1}{2}}=2.29 \times 10^{-4}[7.16-\kappa(A)] \alpha_{\eta}{ }^{3}
$$

for $\operatorname{poly}(\alpha$-methylstyrene $)$ and

$$
k_{\mathrm{s}} / \bar{M}_{w}{ }^{\frac{1}{2}}=2.87 \times 10^{-4}[7.16-\kappa(A)] \alpha_{\eta}{ }^{3}
$$

for polystyrene.

$k_{\mathrm{s}}$ at the $\theta$-Condition. At the $\theta$-condition, eq 11 shows that $k_{\mathrm{s}}$ is a linear function of $M^{\frac{1}{2}}$, because $\kappa(A)$ is a constant at $A=0$, although the value depends upon the model chosen to describe

\footnotetext{
* Strictly, when $\alpha$ is the expansion factor based on the radius of gyration, the relationship should be given by the form: $\alpha^{3}=1+1.91 z$ (M. Fixman ${ }^{17}$ ). Here, eq 14 was employed for simplicity in further discussion, because $z$ is small in the vicinity of $\theta$ condition.
}

the hydrodynamic interaction.

In Figures 6 and 7, the values of $k_{\mathrm{s}}$ at the $\theta$-temperature obtained in this work and reported by other investigators are plotted against $\bar{M}_{w}^{\frac{1}{2}}$. The authors' data for $\operatorname{poly}(\alpha$-methylstyrene $)$ are seen to agree with those of Nagasawa, et al. ${ }^{7}$ and Kurata, et al. ${ }^{8}$ although their measurements

\begin{tabular}{|c|c|c|c|}
\hline System & $\begin{array}{l}\bar{v}_{\theta} \\
\mathrm{m} l / g\end{array}$ & $\begin{array}{l}\rho_{0 \theta} \\
\mathrm{g} / \mathrm{m} l\end{array}$ & $\begin{array}{c}\eta_{0 \theta}, \\
\mathrm{g} \mathrm{cm}^{-1} \mathrm{sec}^{-1}\end{array}$ \\
\hline $\begin{array}{l}\text { Poly }(\alpha \text {-methylstyrene) in } \\
\text { cyclohexane, } 38.2^{\circ} \mathrm{C}\end{array}$ & $0.88_{9}$ & $0.761_{0}$ & $7.1_{6} \times 10^{-3}$ \\
\hline $\begin{array}{l}\text { Polystyrene in } \\
\text { cyclohexane, } 35.0^{\circ} \mathrm{C}\end{array}$ & $0.92_{8} \mathrm{~b}$ & $0.764_{0}$ & $7.6_{0} \times 10^{-3}$ \\
\hline
\end{tabular}
were made at $39.0^{\circ} \mathrm{C}$ as the $\theta$-temperature. It is also seen that the authors' data for polystyrene

Table V. Characteristic values at the $\theta$-temperature ${ }^{a}$

a $\bar{v}_{\theta}$, partial specific volume of polymer; $\rho_{0 \theta}$, density of solvent; $\eta_{00}$, viscosity of solvent.

b By Mandelkern, et al. ${ }^{10}$

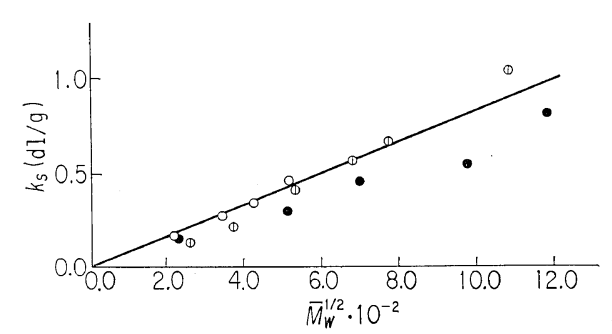

Figure 6. Plots of $k_{\mathrm{s}}$ vs. $\bar{M}_{w}^{\frac{1}{2}}$ for $\operatorname{poly}(\alpha$-methylstyrene) in cyclohexane at the $\theta$-condition: $\bigcirc$, this work $\left(38.2^{\circ}\right)$; (1), Nagasawa, et al..$^{(}\left(39.0^{\circ} \mathrm{C}\right)$; -, Kurata, et al. ${ }^{8}$; solid line, obtained from the data in this work.

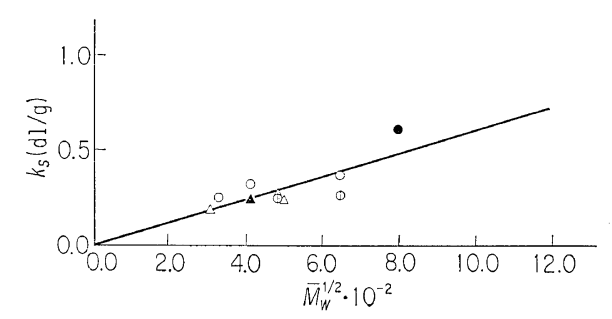

Figure 7. Plots of $k_{\mathrm{s}}$ vs. $\bar{M}_{w}^{\frac{1}{2}}$ for polystyrene in cyclohexane at the $\theta$-temperature $\left(35.0^{\circ} \mathrm{C}\right): \bigcirc$, this work; , Wales, et al. ${ }^{14} ; \triangle$, Billick ${ }^{15}$; $\ominus$, Homma, et al. ${ }^{13} ; \boldsymbol{\Delta}$, Billick $^{5}$; solid line, obtained from the data both in this work and in the earlier reports. 
satisfactorily agree with those earlier reports. ${ }^{5,13-15}$

From these figures, it is concluded that $k_{\mathrm{s}}$ at the $\theta$-state can be satisfactorily expressed as the linear function of $\bar{M}_{w}^{\frac{1}{2}}$. This result as well as those obtained by the other investigators ${ }^{5,7,8,12}$ fulfills the essential requirement of Pyun and Fixman theory at the $\theta$-condition. ${ }^{4}$

The values for $\kappa(A)$ obtained from the slopes of the solid lines in these figures are 3.6 for $\operatorname{poly}(\alpha$-methylstyrene $)$ and 5.0 for polystyrene, respectively.

$k_{\mathrm{s}}$ in the Vicinity of $\theta$-Condition. The values of $k_{\mathrm{s}} / \bar{M}_{w}{ }^{\frac{1}{2}}$ obtained are plotted against $\alpha_{\eta}{ }^{3}$ in Figure 8 for $\operatorname{poly}(\alpha$-methylstyrene $)$ and in Figure 9 for polystyrene.

It is found that $k_{\mathrm{s}} / \bar{M}_{w}^{\frac{1}{2}}$ for each polymer increases monotonically with increasing $\alpha_{\eta}{ }^{3}$ and that the variation of $k_{\mathrm{s}} / \bar{M}_{w}^{\frac{1}{2}}$ with $\alpha_{\eta}{ }^{3}$ appears to be expressed by a single line, regardless of the molecular weight of the sample.

In the same figures, the variations of $k_{\mathrm{s}} / \bar{M}_{w}^{\frac{1}{2}}$ with $\alpha_{\eta}{ }^{3}$ calculated by eq 16 or 17 and 15 are shown by the dotted lines.

The dotted line is close to the experimental results in the region $\alpha_{\eta}{ }^{3} \approx 1$, and the discrepancy between calculated and experimental results increases with increasing $\alpha_{\eta}{ }^{3}$. One might expect that another choice of the relationship between $A$ and $\alpha_{\eta}$ would change the trend of the calculated curve. For example, one could take the equation.

$$
A=14.16\left(\alpha_{\eta}{ }^{2}-1\right)
$$

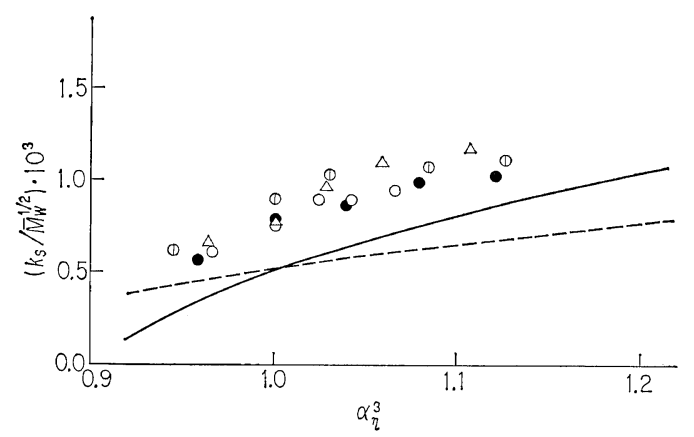

Figure 8. Variations of $k_{\mathrm{s}} / \bar{M}_{w}^{\frac{1}{2}}$ with $\alpha_{\eta}^{3}$ for poly$(\alpha$-methylstyrene) in cyclohexane near the $\theta$-point: ○, PMS-6; $\triangle$, PMS-03; ๑, PMS-227; (1), PMS-10; dotted line, calculated through eq 16 by using eq 15; solid line, calculated through eq 16 by using eq 18 .

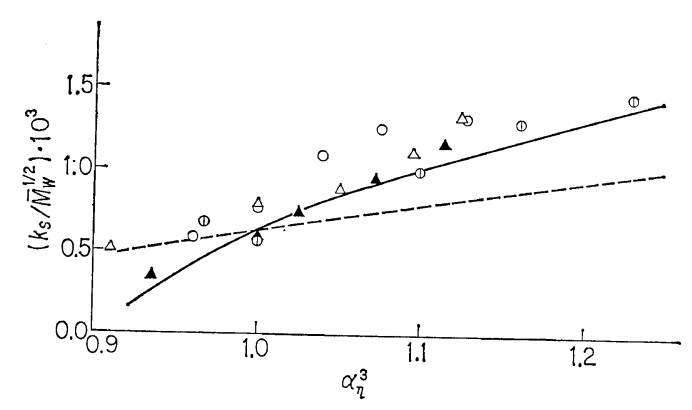

Figure 9. Variations of $k_{\mathrm{s}} / \bar{M}_{w}^{\frac{1}{2}}$ with $\alpha_{\eta}^{3}$ for polystyrene in cyclohexane near the $\theta$-point: $\bigcirc$, PS9; $\triangle$, PS-16; (1), PS-41; $\Delta$, Billick ${ }^{5}$; dotted line, calculated by eq 17 by using eq 15 ; solid line, calculated by eq 17 with eq 18 .

which was empirically estimated by $\mathrm{Sakai}^{18}$ in his investigation on Huggins' constant on the basis of the Peterson and Fixman theory. ${ }^{19}$ The calculated values of $k_{\mathrm{s}} / \bar{M}_{w}^{\frac{1}{2}}$ by eq 18 are shown by the solid lines in Figures 8 and 9 for the respective polymers. Both figures indicate that the solid line fits the experimental data better than the dotted line. This results shows that the calculated $k_{\mathrm{s}} / \bar{M}_{w}^{\frac{1}{2}}$ is considerably affected by the selection of the relationship between $A$ and $\alpha_{\eta}$.

Summarizing, the behavior of experimental $k_{\mathrm{s}} / \bar{M}_{w}{ }^{\frac{1}{2}}$ can be satisfactorily expressed by the Pyun and Fixman theory, though the selection of a more appropriate relationship between $A$ and $\alpha_{\eta}$ is left for a further discussion.

Extension to Large Expansion of Polymer. In Figures 10 and 11, the solid and dotted lines show values of $k_{\mathrm{s}} / \bar{M}_{w}{ }^{\frac{1}{2}}$ for each polymer obtained by using eq 18 and 15 , respectively. For comparison, the experimental data of $k_{\mathrm{s}} / \bar{M}_{w}{ }^{\frac{1}{2}}$ obtained in this work and those obtained by other investigators in various solvents ${ }^{2,5,7,20,21}$ are plotted.

It appears that the experimental data for each polymer can be represented by a single curve which tends to increase with increasing $\alpha_{\eta}{ }^{3}$, regardless of the differences in solvent and in temperature, and that the solid lines based on eq 18 fit the experimental data satisfactorily.

It is concluded that the discrepancy between calculated and experimental results depends mainly on the relationship between $A$ and $\alpha_{\eta}$ and that the present treatment of the Pyun and 


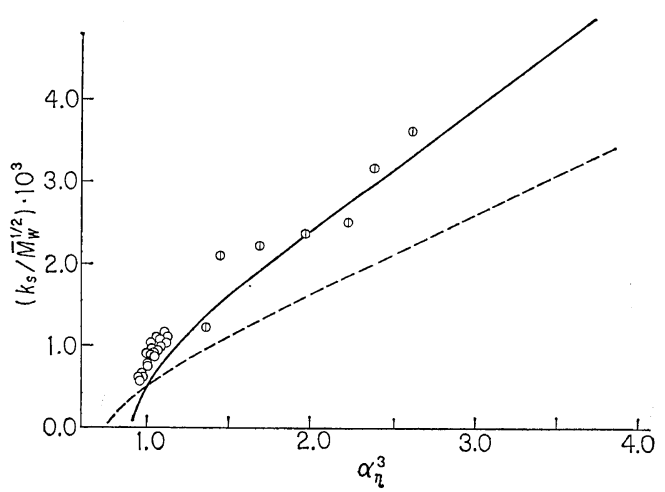

Figure 10. Variations of $k_{\mathrm{s}} / \bar{M}_{w^{\frac{1}{2}}}$ with $\alpha_{\eta}^{3}$ for poly( $\alpha$-methylstyrene): $\bigcirc$, in cyclohexane (this work); (1), in toluene (Nagasawa, et al. ${ }^{7}$ ); solid line, calculated by eq 16 with eq 18 ; dotted line, calculated by eq 16 with eq 15 .

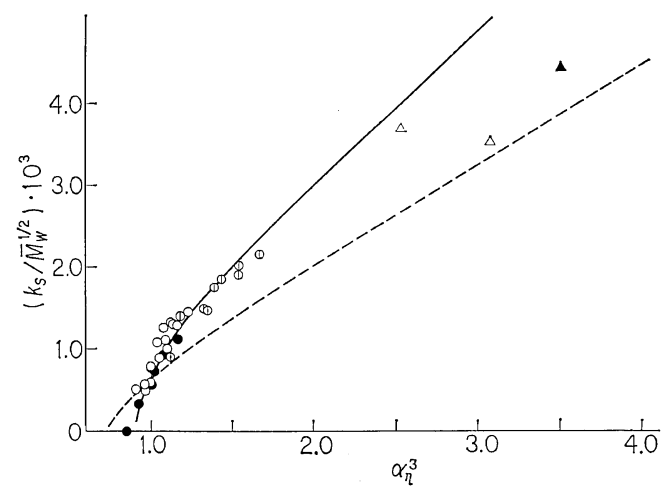

Figure 11. Variations of $k_{\mathrm{S}} / \bar{M}_{w}^{\frac{1}{2}}$ with $\alpha_{\eta}^{3}$ for polystyrene: $\bigcirc$, in cyclohexane (this work); $\odot$, in cyclohexane (Billick ${ }^{5}$ ); (1), in butanone (Newman, et al. ${ }^{20}$, Shick, et al. ${ }^{21}$, Van Holde, et al. $\left.{ }^{2}\right) ; \boldsymbol{\Delta}$, in chloroform (Newman, et al. $\left.{ }^{20}\right) ; \triangle$, in toluene (Newman, et al. ${ }^{20}$, Van Holde, et al. ${ }^{2}$ ); solid line, calculated eq 17 with eq 18; dotted line, calculated by eq 17 with eq 15 .

Fixman theory may in effect be used for a further detailed investigation of $k_{\mathrm{s}}$-behavior if an appropriate relationship between $A$ pnd $\alpha_{\eta}$ can be found.

\section{CONCLUSION}

The requirement of the Pyun and Fixman theory at the $\theta$-condition was fulfilled by the $k_{\mathrm{s}}$-data obtained in this work and in earlier reports.

The $k_{\mathrm{s}}$-behavior in the vicinity of $\theta$-condition as well as in the region of larger expansion of polymer was found to be satisfactorily expressed by the theory of Pyun and Fixman when an appropriate relationship between the segmentsegment interaction parameter and the expansion factor was employed.

Acknowledgement. The authors wish to thank Prof. Mitsuru Nagasawa, of the Department of Synthetic Chemistry, Nagoya University, for the supply of the poly ( $\alpha$-methylstyrene) samples, and Dr. Tsukasa Sakai, of the Textile Research Institute of the Japanese Government, for his helpful suggestions concerning the theoretical treatment in this work. They also wish to express their gratitude to Dr. Toshio Kamata and Mr. Shigeru Hattori, of the Government Chemical Industrial Research Institute, Tokyo, for providing facilities for the light-scattering and osmotic-pressure measurements and also to Dr. Tokihiko Masuzawa, of this laboratory, for his kind assistance in the osmometry.

\section{REFERFNCES}

1. J. M. Burgers, Proc. Nat. Acad. Sci., Amsterdam, 45, 9 (1942).

2. K. E. Van Holde and M. Wales, J. Polym. Sci., 14, 81 (1954).

3. H. Yamakawa, J. Chem. Phys., 36, 2995 (1962).

4. C. W. Pyun and M. Fixman, J. Chem. Phys., 41, 937 (1964).

5. I. H. Billick, Preprints, 142th Annual Meeting of the American Chemical Society, Chicago, 1964; Amer. Chem. Soc., Div. Polym. Chem., 5(2), 855 (1964).

6. A. Kotera, T. Saito, N. Yamaguchi, A. Wada, Y. Taniyama, S. Usami and T. Sakai, Preprints, SPSJ 12th Annual Meeting, Tokyo, May 1963, p 97.

7. I. Noda, S. Saito, T. Fujimoto, and M. Nagasawa, J. Phys. Chem., 71, 4048 (1967).

8. M. Abe, K. Sakato, T. Kageyama, M. Fukatsu, and M. Kurata, Bull. Chem. Soc. Japan, 41, 2330 (1968).

9. J. M. G. Cowie, S. Bywater, and D. J. Worsfold, Polymer (London), 8, 105 (1967).

10. D. McIntyre, A. Wims, L. C. Williams, and L. Mandelkern, J. Phys. Chem., 66, 1932 (1962).

11. H. Fujita, "Mathematical Theory of Sedimentation Analysis", Academic Press, New York, N. Y., 1962.

12. N. Donkai and T. Kotaka, J. Polym. Sci., Part $A-2,6,1457$ (1968). 
A. Kotera, T. Saito, and T. Hamada

13. T. Homma, K. Kawahara, H. Fujita, and M. 18. T. Sakai, J. Polym. Sci., Part A-2, 6, 1535 (1968); Ueda, Makromol. Chem., 67, 132 (1963). private communication.

14. M. Wales and S. J. Rehfeld, J. Polym. Sci., 62, 179 (1962).

15. I. H. Billick, J. Phys. Chem., 66, 1941 (1962).

16. T. Svedberp and K. O. Pederson, "The Ultracentrifuge", Oxford University Press, London 1940.

19. J. M. Pederson and M. Fixman, J. Chem. Phys., 39, 2516 (1963).

20. S. Newman and F. Eirich, J. Colloid Sci., 5, 541 (1950).

21. A. F. Shick and S. J. Singer, J. Phys. Chem., 54, 1028 (1950).

17. M. Fixman, J. Chem. Phys., 36, 3123 (1962). 